\title{
Chemical contaminants migration from food contact materials into aqueous extracts
}

\author{
Elena Loredana Ungureanu ${ }^{1,2, *}$, Gabriel Mustatea ${ }^{2}$, and Mona Elena Popa ${ }^{1}$ \\ ${ }^{1}$ University of Agronomic Science and Veterinary Medicine, Faculty of Biotechnology, 59 Mărăşti \\ Boulevard, District 1, Bucharest, 011464, Romania \\ ${ }^{2}$ National Research \& Development Institute for Food Bioresources, 5th Baneasa Ancuta, \\ 020323,Bucharest, Romania
}

\begin{abstract}
Cardboard packaging is widely used in the food industry, especially as secondary or tertiary packaging, or as transport packaging. In most cases, these packs may contain certain chemical contaminants that can be accidentally transferred to packaged foods. These contaminants include Bisphenol A (BPA) and Formaldehyde, which can cause significant adverse effects, especially to vulnerable persons. For this reason, the purpose of this study was to analyze by a UV - VIS spectrophotometric method the content of BPA and Formaldehyde from 17 corrugated board samples from Romanian producers. BPA concentrations varied between $0.044 \mathrm{mg} / \mathrm{dm}^{2}$ and $0.090 \mathrm{mg} / \mathrm{dm}^{2}$, while Formaldehyde concentrations were lower than $0.048 \mathrm{mg} / \mathrm{dm}^{2}$. The results were compared with the legislation in force to establish their compliance for contact with food.
\end{abstract}

\section{Introduction}

Nowadays, there has been an increase in the production of packaging materials for all industries. This is due to the fact that each product is sold in a package. Packaging has a vital importance especially in the food industry where they are used as food contact materials (FCM), whose role is to preserve, to protect, to promote the food products throughout the food chain [1].

According to EU Regulation no. 1935/2004 [2], FCM must not release chemicals that may endanger consumers health, affect product sensory or nutritional properties, or alter food composition [3].

These chemicals, called food contact chemicals (FCC), are chemical constituents from food contact materials that are added to these packaging, and which, under certain conditions, can migrate into the packaged food product [4].

The main types of FCM used in the food industry are represented by plastics, glass, paper and cardboard, metallic materials [5]. These products must be safe for food contact. Their compliance with regulations in force, depending on the type of material is necessary to be tested [1].

\footnotetext{
${ }^{*}$ Corresponding author: elena ungureanu93@yahoo.com
} 
The widespread use of paper and cardboard packaging, as primary, secondary or tertiary packaging, is due to the low price, reduced weight, availability on the packaging market, ease of storage, but also good mechanical properties [5].

In connection with substances that can migrate from this type of packaging, their number is quite large. Formaldehyde and Bisphenol A (BPA) are two chemical compounds (Figure 1) which can cause adverse effects on the consumers health. Most of the chemical contaminants that can migrate, including formaldehyde and BPA, come either from the printing inks, or from the adhesives used in the process of obtaining the packaging [1].<smiles>CC(C)(c1ccc(O)cc1)c1ccc(O)cc1</smiles>

a)<smiles>C=O</smiles>

b)

Fig. 1. BPA (a) and Formaldehyde (b) chemical formulas.

These compounds can migrate from the packaging into the product under certain conditions, being influenced by direct or indirect contact with the food, their chemical properties, their initial concentration, contact time and temperature [1].

The aim of this study was to assess the possible contamination with BPA and Formaldehyde of several types of cardboard from different Romanian producers, in order to evaluate the compliance with the legislation in force.

\section{Material and method}

\subsection{Sample description}

A total of 17 samples of corrugated cardboard (CB) were used in this study. These samples, presented in Table 1 were collected from different Romanians producers.

Table 1. Characteristics of the analyzed samples.

\begin{tabular}{|c|l|}
\hline Sample no. & \multicolumn{1}{c|}{ Sample description } \\
\hline 1 & CB type 3 (TL-W-TL), natural, E flute \\
\hline 2 & CB type 3 (K-W-TL), natural, E flute \\
\hline 3 & CB type 3 (TA-W-CO), natural, E flute \\
\hline 4 & CB type 3 (TL-W-TL), natural, E flute \\
\hline 5 & CB type 3 (K-W-TL), natural, B flute \\
\hline 6 & CB type 3 (TA-W-TL), white, B flute \\
\hline 7 & CB type 3 (TL-W-CO), natural, C flute \\
\hline 8 & CB type 3 (TL-W-TL), natural, C flute \\
\hline 9 & CB type 3 (TA-W-TL), white, C flute \\
\hline 10 & CB type 5 (TA-W-TL-W-TL), white, BC flute \\
\hline 11 & CB type 3 (TL-W-TL), natural, E flute \\
\hline 12 & CB type 3, natural, E flute \\
\hline 13 & CB type 3, natural, B flute \\
\hline 14 & CB type 3, natural, C flute \\
\hline 15 & CB type 3, natural, C flute \\
\hline 16 & CB type 3, white, E flute \\
\hline 17 & CB type 5, natural, BC flute \\
\hline
\end{tabular}




\subsection{Reagents}

All chemicals used in this study were of analytical reagent grade. Bisphenol A (2,2 - Bis(4hydroxyphenyl) propane), Nitric Acid (HNO3 65\%), Formaldehyde solution (370 g/L), Anhydrous Ammonium Acetate, Acetic Acid (99\%) and 2,4-Pentandione were purchased from Merck. All dilutions were performed using ultrapure water (18.2 M $\Omega . \mathrm{cm})$. All glassware used was cleaned and decontaminated with $10 \%$ HNO3.

\subsection{Equipment}

BPA and Formaldehyde analysis was performed by UV/VIS molecular spectroscopy, using a Jasco v550 UV/VIS Spectrophotometer, provided with a deuterium lamp and a wavelength range between $190 \mathrm{~nm}$ and $900 \mathrm{~nm}$. A GFL type water bath (Burgwedel, Germany) for preparing the solutions and an OHAUS analytical balance for weighing the samples were also used.

\subsection{Preparation of water extract}

Sampling, preparation and extraction of samples were performed according to SR EN 645: 1997 standard [6]. For the preparation of the extract, 10 grams $( \pm 0.1 \mathrm{~g})$ of each sample were used. Samples were cut into small pieces, were immersed in $200 \mathrm{~mL}$ water, and after 24 hours at $23^{\circ} \mathrm{C}\left( \pm 2{ }^{\circ} \mathrm{C}\right)$, the extract is filtered, brought to a $250 \mathrm{~mL}$ volumetric flask and then analyzed.

\subsection{Preparation of standard solutions}

For BPA calibration curve, $0.1 \mathrm{~g}$ of BPA was weighted in a volumetric flask and then filled up to $100 \mathrm{ml}$ with ethanol. The solution was diluted 100 times with ultrapure water for obtaining solution B. The standard solutions were prepared, from solution B, according to Table 2 .

Table 2. Preparation of standard solutions for BPA calibration curve.

\begin{tabular}{|l|l|l|l|l|l|l|l|l|l|}
\hline Solution B (mL) & 1 & 2 & 3 & 4 & 5 & 6 & 7 & 8 & 9 \\
\hline Ultrapure water (mL) & 9 & 8 & 7 & 6 & 5 & 4 & 3 & 2 & 1 \\
\hline
\end{tabular}

Calibration curve for formaldehyde was performed according to SR EN 1541: 2003 [7]: $5 \mathrm{~mL}$ of formaldehyde solution are diluted up to $1000 \mathrm{~mL}$ in a volumetric flask (Solution I) with ultrapure water. Then, another 20 times dilution is performed for obtaining Solution II, which, finally is diluted 100 times to obtain Solution III. $1 \mathrm{~mL}$ of the final solution contains approximately $0.001 \mathrm{mg}$ of formaldehyde. The calibration solutions were prepared, from solution III, as presented in Table 3.

Table 3. Preparation of Formaldehyde calibration solutions.

\begin{tabular}{|l|c|c|c|c|c|c|}
\hline Solution III (mL) & 1 & 5 & 10 & 15 & 20 & 25 \\
\hline 2,4-Pentandione reagent (mL) & 5 & 5 & 5 & 5 & 5 & 5 \\
\hline
\end{tabular}

\subsection{Calibration}

Calibration curve for each element was performed using reagents described above. The calibration curve for BPA and Formaldehyde reveal a good linearity over the whole range 
of concentrations. Also, for both chemical contaminants a recovery of over $95 \%$ and a regression coefficient higher than 0.995 was obtained. The limits of detection and quantification for the analyzed contaminants were $0.01 \mathrm{mg} / \mathrm{L}$, respectively $0.03 \mathrm{mg} / \mathrm{L}$ for BPA and $0.004 \mathrm{mg} / \mathrm{L}$ and $0.012 \mathrm{mg} / \mathrm{L}$ for Formaldehyde.

\subsection{Sample preparation}

$10 \mathrm{ml}$ of extract were acidified with $\mathrm{HNO} 365 \%$ and boiled for 25 minutes. After cooling, 1 $\mathrm{ml}$ of $\mathrm{KOH} 50 \%$ was added in order to complete reaction. If BPA is present the solution is turning yellow. The solution is then measured at $430 \mathrm{~nm}$. The control solution was prepared in the same way, except for the $10 \mathrm{ml}$ which were of ultrapure water.

Formaldehyde reacts with 2,4-Pentandione, in the presence of ammonium acetate, forming 3,5-diacetyl-1,4-dihydrolutidine. The extract is then measured at $410 \mathrm{~nm}$ wavelength. Preparation of calibration solutions and samples was performed according to SR EN 1541:2003 [7].

\subsection{Calculation of results}

BPA concentration calculation was performed using Equation (1).

$$
C=(C s-C c) \times 1000 / V 0
$$

$\mathrm{C}$ is BPA concentration (in $\mathrm{mg} / \mathrm{L}$ ), $\mathrm{Cs}$ is the BPA concentration of the sample $(\mathrm{mg} / 10$ $\mathrm{ml}$ extract), $\mathrm{Cc}$ is the BPA concentration of the control ( $\mathrm{mg} / 10 \mathrm{ml}$ standard solution), $\mathrm{V} 0$ is the volume of extract used $(10 \mathrm{~mL})$.

Formaldehyde concentration calculation was performed using Equation (2).

$$
C f=C x(V 0 / V 1) x(b / 100) \times(1 / G)
$$

$\mathrm{Cf}$ is Formaldehyde concentration (in $\mathrm{mg} / \mathrm{dm} 2$ ), $\mathrm{C}$ is formaldehyde concentration from calibration curve (in $\mathrm{mg}$ ), $\mathrm{V} 0$ is the total volume of the extract $(250 \mathrm{~mL}), \mathrm{V} 1$ is the volume taken for testing $(25 \mathrm{~mL}), \mathrm{b}$ is sample weight (in $\mathrm{g} / \mathrm{m} 2$ ) and $\mathrm{G}$ is the mass of the sample (in grams).

\section{Results and discussion}

BPA analysis method is based on the reaction between BPA and HNO3 with the formation of aromatic compounds (ortho-phenols) of yellow color. Analyzing the results presented in Figure 2, the BPA concentrations varied between $0.044 \mathrm{mg} / \mathrm{dm} 2$ and $0.090 \mathrm{mg} / \mathrm{dm} 2$.

According to CEPI Guide, 2012 [8], the maximum allowed limit for BPA in paper and cardboard intended for food contact is $0.1 \mathrm{mg} / \mathrm{dm} 2$. All values obtained are below the limit.

Regarding formaldehyde, according to the EC Resolution ResAP version 3/2007 [9], the maximum allowed limit is $2.5 \mathrm{mg} / \mathrm{dm} 2$. As can be observed analyzing the results in Table 4 , all values are much lower than the limit.

The highest values for both BPA and Formaldehyde were found in sample 13, which is a 3-layer corrugated board. However, the values obtained are higher than in the case of samples 10 and 17 which are cardboard samples consisting of 5 layers. This may be due to the raw material (paper) from which the layers were obtained. 


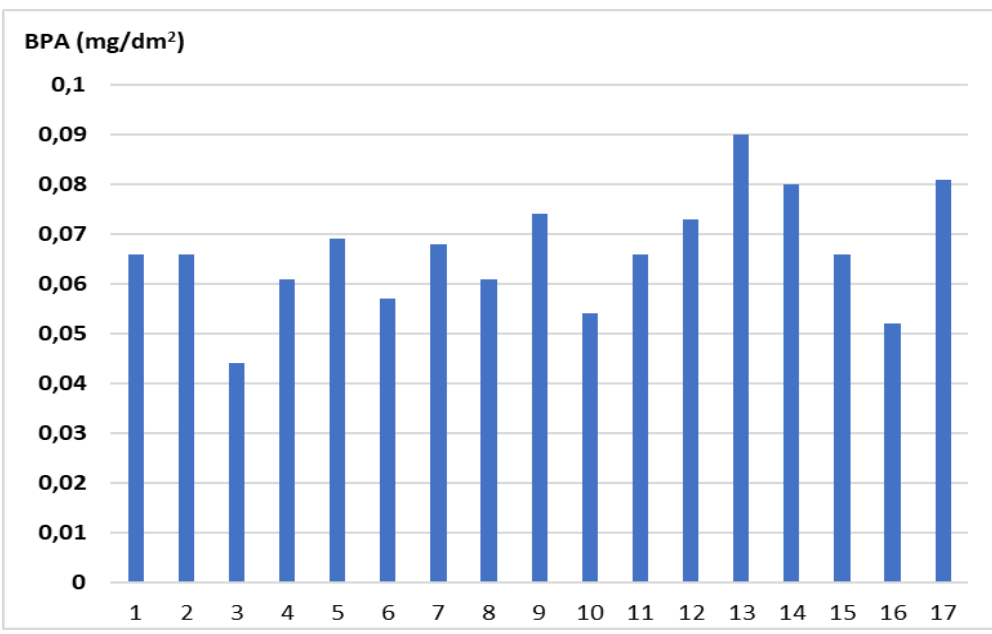

Fig. 2. BPA analysis results.

Table 4. Formaldehyde concentration in analyzed samples.

\begin{tabular}{|c|c|}
\hline Sample no. & $\begin{array}{c}\text { Formaldehyde } \\
\text { concentration }\left(\mathbf{m g} / \mathbf{d m}^{\mathbf{2}}\right)\end{array}$ \\
\hline 1 & 0.017 \\
\hline 2 & 0.008 \\
\hline 3 & $<0.004$ \\
\hline 4 & $<0.004$ \\
\hline 5 & 0.022 \\
\hline 6 & $<0.004$ \\
\hline 7 & $<0.004$ \\
\hline 8 & 0.033 \\
\hline 9 & $<0.004$ \\
\hline 10 & $<0.004$ \\
\hline 11 & $<0.004$ \\
\hline 12 & 0.04 \\
\hline 13 & 0.048 \\
\hline 14 & 0.032 \\
\hline 15 & 0.028 \\
\hline 16 & 0.014 \\
\hline 17 & 0.014 \\
\hline & \\
\hline
\end{tabular}

\section{Conclusions}

In this article a simple and rapid method was used for BPA and Formaldehyde analysis in corrugated cardboard used as FCM.

All the results obtained are below the maximum allowed limits, for both BPA and Formaldehyde. Regarding the BPA content, the concentrations found were higher than those in the literature $[10,11]$. The differences may occur due to the analytical methods used.

In the case of formaldehyde, the values obtained are comparable with some results from the literature [12]. One reason could be that the UV-VIS method is the standardized method for determining the formaldehyde in paper and board used for contact with food. The 
differences that may occur may be due to the experimental conditions and the heterogeneity of the samples.

Taking into account the obtained results, all the samples can be used in contact with food. Further, much more detailed studies are needed to demonstrate this.

This work was supported by a grant of the Romanian Ministry of Education and Research, through Sectorial Plan, contract no. 3PS/2019.

\section{References}

1. A. Icoz, B. Eker, 1st International Conference on Quality of Life, 201-210 (2016)

2. Regulation (EC) no. 1935/2004 of the European Parliament and the Council of 27 October 2004 on materials and articles intended to come into contact with food and repealing Directives 80/590/EEC and 89/109/EEC.

3. B. Y. Gok, D. Akpinar, D. Hittite, Journal of Science \& Engineering 7(3), 163-168 (2020)

4. J. Muncke, A.M. Andersson, T. Backhaus, J.M. Boucher, B.C. Almroth, A.C. Castillo, J. Chevrier, B.A. Demeneix, et.al., M. Environ Health. 19(1), 25 (2020)

5. M. Nowacka, K. Rybak, A. Wiktor, A. Mika, P. Boruszewski, J. Woch, K. Przybysz, D. Witrowa-Rajchert, Food Cont. 93, 183 - 190 (2018)

6. SR EN 645:1997 - Paper and board intended to come into contact with foodstuffs Preparation of a cold-water extract.

7. SR EN 1541: 2003 - Paper and board intended to come into contact with foodstuffs Determination of formaldehyde in an aqueous extract.

8. The Industry Guideline for the Compliance of Paper \& Board Materials and Articles for Food Contact (CEPI, 2012)

9. EC Resolution ResAP version 3/2007

10. A. Ozaki, C. Kawasaki, Y. Kawamura, K. Tanamoto, J. Food. Hyg. Soc. Jpn. 47(3), 99-104 (2006)

11. A. Jurek, E. Leitner, Food Addit. Contam. Part A 34(7), 1225-1238 (2017)

12. C.E. Dogan, R. Sanci, Food Addit. Contam. Part B Surveill 8(3), 221-226 (2015) 